\title{
A Nova Perspectiva da Gestão na Educação e sua aplicação no Estado do Piauí
}

\author{
The New Perspective of Management in Education and its application in the State of Piauí \\ La Nueva Perspectiva de la gestión en la Educación y su Aplicación en el Estado de Piauí
}

Recebido: 30/06/2021 | Revisado: 07/07/2021 | Aceito: 08/07/2021 | Publicado: 09/07/2021

\author{
Tássio Mascarenhas de Carvalho \\ ORCID: https://orcid.org/0000-0001-7416-919X \\ Centro Universitário Campo Limpo Paulista, Brasil \\ Faculdade Estácio de Teresina, Brasil \\ E-mail: metassiocarvalho@gmail.com \\ Izabel Rodrigues da Silva \\ ORCID: https://orcid.org/0000-0003-3094-3379 \\ ATSD-PI, Brasil \\ E-mail: izabel6418@gmail.com \\ Rafael Soares Silva \\ ORCID: https://orcid.org/0000-0001-9994-6653 \\ Universidade de São Paulo, Brasil \\ E-mail: silva.rafael@usp.br
}

\begin{abstract}
Resumo
Este estudo tem como objetivo apresentar as novas perspectivas da gestão educacional e sua aplicação no Estado do Piauí. Para tal, lançou-se mão de uma pesquisa tipo descritiva exploratória, através de uma revisão bibliográfica, utilizando como fontes de pesquisa a Revista Brasileira de Educação - RBE - indexada na base de dados SCIELO, bem como artigos de outras bases, monografias, dissertações e livros. Foi utilizado também a análise tipo documental das publicações referentes ao Piauí nas páginas eletrônicas oficiais. A democratização na gestão escolar é um marco para o novo sistema educacional, tendo como bases legais a Constituição Federal Brasileira e a Lei de Diretrizes e Bases da Educação Nacional. No Piauí, a prática da inovação na gestão educacional, principalmente no ensino básico, vem colocando o Estado à frente na participação de programas educacionais e incentivo na capacitação de gestores. Portanto, o Estado do Piauí é um propulsor, no que tange à gestão participativa na educação, estimulando as escolas a participarem de programas como o Prêmio Gestão Escolar e também investindo na formação e capacitação de gestores, com a finalidade de manter o compromisso com a educação, incorporando novas estratégias à maneira de gerir, com a finalidade de subsidiar o conhecimento e aperfeiçoando as ferramentas de gestão.
\end{abstract}

Palavras-chave: Gestão democrática; Inovação na gestão educacional; Educação; Piauí.

\begin{abstract}
This study aims to present new perspectives of educational management and its application in the state of Piauí. To this end, it employed a literature review of exploratory descriptive using as source the Brazilian Journal of Education RBE - indexed in SciELO database, as well as articles from other bases, monographs, dissertations and books. Was also used analysis type documentary of publications relating to the web pages officers of Piauí. Democratization in school management is a milestone for the new educational system, with the legal basis to the Brazilian Federal Constitution and the Law of Guidelines and Bases of National Education. In the Piauí, the practice of innovation in management education, especially basic education, comes putting the state ahead of participation in educational programs and encourage the training of managers. Therefore, the State of Piauí is a propellant in terms participatory management in education, encouraging schools to participate in programs such as School Management Award and also investing in the training of managers in order to maintain the commitment to education incorporating new strategies to manage the way, with the aim of supporting and improving knowledge management tools.
\end{abstract}

Keywords: Democratic management; Innovation in educational management; Education; Piauí.

\section{Resumen}

Este estudio tiene como objetivo presentar nuevas perspectivas sobre la gestión educativa y su aplicación en el estado de Piauí. Para ello, se utilizó una investigación exploratoria descriptiva, a través de una revisión de la literatura, utilizando como fuentes de investigación la Revista Brasileira de Educação - RBE - indexada en la base de datos SCIELO, así como artículos de otras bases de datos, monografías, disertaciones y libros. También se utilizó el análisis de tipo documental de las publicaciones referentes a Piauí en los sitios web oficiales. La democratización de la gestión escolar es un hito para el nuevo sistema educativo, basado en la Constitución Federal de Brasil y la Ley de Lineamientos y Bases de la Educación Nacional. En Piauí, la práctica de la innovación en la gestión educativa, especialmente en la educación básica, ha ido colocando al Estado a la vanguardia de la participación en programas educativos e incentivos para la formación de directivos. Por tanto, el Estado de Piauí es un impulsor en cuanto a la 
gestión participativa en la educación, incentivando a las escuelas a participar en programas como el Premio a la Gestión Escolar e invirtiendo también en la formación y formación de los directivos, con el fin de mantener el compromiso con la educación, incorporando nuevas estrategias a la forma de gestionar, con el fin de subsidiar el conocimiento y mejorar las herramientas de gestión.

Palabras clave: Gestión democrática; Innovación en la gestión educativa; Educación; Piauí.

\section{Introdução}

A gestão, pelo sentido literal da palavra, é um termo abrangente que necessita de um entendimento claro e conciso, pois varia conforme o ramo em que se pretende trabalhar; por isso, é de suma importância compreender seu significado, uma vez que seu conceito de forma genérica pode gerar diversas implicações.

Segundo Aurélio (2010, p. 378), a gestão pode ser entendida como "s.f. Ação de gerir. / Gerência, administração. // Gestão de negócios, diz quando uma pessoa administra os negócios de outra, por eles se responsabilizando solidariamente, mas sem autorização legal”.

Quando se trata de gestão no setor educacional, é possível ver na literatura a notoriedade dada ao tema, uma vez que estudos sobre gestão apontam que, desde o final da década de 70, pesquisadores e estudiosos desta área, perceberam o impacto da gestão participativa na eficácia das escolas como organizações (Paro, 1998).

Para entender melhor de forma operacional a gestão é necessária ressaltar que segundo Brasil (2006), não há um consenso sobre a diferença entre os termos gerir e administrar, pois, estes conceitos por algumas vezes são dados ora como sinônimos ora como antônimos. Em alguns momentos o termo gerir pode ser entendido como parte integrante do processo administrativo e em outros casos apresentar-se um novo conceito da prática administrativa.

Sendo assim, a gestão na educação pode ser entendida como um processo político-administrativo fortemente situado na abordagem em que se insere, onde as atividades sociais relacionadas à educação acontecem de forma consecutiva e operacional em um modelo organizado, com direção focada no contexto educacional e de maneira a permitir a execução das ações educacionais (Bordignon; Gracindo, 2000, apud, Ferreira; Aguiar, 2000, p. 147-176).

Ainda nesta área de atuação, é importante ressaltar a importância do processo democrático no fortalecimento da gestão educacional, uma vez que a democratização do ensino e da escola implica aprendizado e vivência do exercício de participação e de tomadas de decisão, tratando-se de um processo que deve ser construído de forma coletiva, considerando a especificidade e a possibilidade histórica e cultural de cada sistema de ensino: municipal, distrital, estadual ou federal (Brasil, 2004a).

É importante ressaltar que gestão da educação é um debate importante à medida que fomenta as políticas públicas direcionadas ao setor da educação. Essas políticas vão além do direcionamento que é efetivado através da gestão que transforma metas e objetivos educacionais em ações concretas.

Partindo dessa linha de ideias, propôs-se apresentar as novas perspectivas da gestão educacional e sua aplicação no Estado do Piauí. A escolha do presente trabalho se dá ao fato da grande relevância social, a discussão do tema é bastante atual, e representa importante contribuição para a gestão da educação, pois se percebe a escassez de estudos publicados no Piauí. Portanto, espera-se que este trabalho contribuía para o enriquecimento teórico acerca da gestão educacional.

\section{Metodologia}

A pesquisa trata-se de um estudo bibliográfico, que para Gil (2007), é desenvolvida a partir de material já elaborado, constituído principalmente de livros e artigos científicos. Embora em quase todos os estudos seja exigido algum tipo de trabalho dessa natureza, há pesquisas desenvolvidas exclusivamente a partir de fontes bibliográficas. Boa parte dos estudos exploratórios pode ser definida como pesquisas bibliográficas, ainda segundo o autor. 
Podemos caracterizar esse estudo ainda quanto a sua natureza, classificando-o como do tipo exploratória descritiva. Para Lakatos e Marconi (2003, p. 188):

Estudos exploratório-descritivos combinados - são estudos exploratórios que têm por objetivo descrever completamente determinado fenômeno, como, por exemplo, o estudo de um caso para o qual são realizadas análises empíricas e teóricas. Podem ser encontradas tanto descrições quantitativas e/ou qualitativas quanto acumulação de informações detalhadas como as obtidas por intermédio da observação participante. Dá-se precedência ao caráter representativo sistemático e, em consequência, os procedimentos de amostragem são flexíveis.

O levantamento bibliográfico ocorreu a partir da delimitação dos critérios de inclusão sendo estes critérios: artigos que remetiam ao tema abordado e/ou temáticas congêneres na íntegra e publicações em português. Como critério de exclusão optou-se por não utilizar textos incompletos e documentos em língua estrangeira.

$\mathrm{Na}$ etapa seguinte, foi feito um levantamento bibliográfico acerca do tema na literatura nacional, tendo como fontes a Revista Brasileira de Educação - RBE - indexada na base de dados SCIELO, bem como artigos de outras fontes, monografias, dissertações e livros. Utilizou-se também, a pesquisa do tipo documental, a fim de analisar os dados extraídos das páginas eletrônicas oficiais referentes ao Piaú́.

A pesquisa documental, segundo Lakatos e Marconi (2003), é caracterizada pela restrição da pesquisa à documentos, que pode ser escrito ou não, podendo ser realizada de forma factual ou após a ocorrência do fenômeno.

Os periódicos selecionados ao final, considerados relevantes e que atendiam à temática proposta para esse estudo, foram analisados, a partir das contribuições dos autores com estudos analíticos constantes dos textos.

\section{Resultados e Discussão}

\subsection{O Processo de construção da democratização na Gestão Educacional}

O século XX, especialmente a década de 70, foi considerado um período delicado na história do Brasil. Segundo Sarubi (2006), nesta época a sociedade brasileira vivenciou um processo de luta pela redemocratização do país, que resultou no ano de 1985, com a transição do regime militar para o regime civil. Nesse período, a sociedade procurou se reorganizar, a fim de resgatar o Estado de Direito, ou seja, a recomposição dos direitos civis e políticos, retirados durante o período militar. Entre os pontos da discussão, estava a qualidade da educação pública e a democratização do ensino. Havia iniciativas com o intuito de formular e implementar políticas educacionais com tendência a incorporar os interesses populares, como também o desenvolvimento de políticas voltadas para a democratização da educação brasileira.

$\mathrm{O}$ que suscitava este processo de mudança, era a busca pela rápida substituição do modelo de escola tradicional inspirado nas organizações militares e fabris, que foi desenvolvido ao longo do século XIX (e que ainda hoje subsiste em muitas organizações escolares, sobretudo ao nível das práticas cotidianas). Neste arsenal, a gestão se dava com ênfase na importância atribuída a dois aspectos: a ordem e a disciplina normativa, onde havia poucas estruturas organizativas, sendo a gestão conduzida de forma linear e vertical, onde a autoridade não se questionava, nem se discutia as decisões. O protótipo de gestor identificava-se com o burocrata autoritário, cuja principal preocupação era o controle da aplicação dos programas e ordens emanadas do Estado (Bacelar, 2008).

Essa ampla discussão da gestão democrática do ensino ganhou destaque em termos de legislação a partir da Constituição Federal de 1988, que a incorpora como um princípio do ensino público na forma da lei. Em verdade, algumas práticas democratizantes pontuais já vinham ocorrendo em diversos sistemas de ensino estaduais e municipais. A promulgação da Constituição tornou obrigatória a adaptação das constituições estaduais e das leis orgânicas dos municípios e do Distrito Federal para incorporação desse princípio e ampliava a possibilidade de ocorrência dessas práticas (Lima, 2002). 
A Constituição de 1988 assegura, ainda, que o ensino deve ser ministrado com base no princípio da gestão democrática, o que a torna única como marco regulatório na educação, especificando em seu Art. 206:

I - Igualdade de condições para o acesso e permanência na escola;

VI - Gestão democrática do ensino público, na forma da lei.

(Brasil, 1988)

Porém, antes mesmo da promulgação da Carta Magna em 1988, a existência de um Fórum nacional em defesa da educação pública ofertada gratuitamente, construído por entidades de todo o país, foi de grande importância para que se alcançasse a participação da população no processo democrático, com o intuído de apontar de forma avançada a ideia de democratização da escola pública, "numa visão da escola como espaço de vivência democrática e de gestão participativa" (Mendonça, 1998, p.59).

Ainda no tocante aos marcos legais da educação (e neste inclui-se a gestão da educação), a Lei de Diretrizes e Bases da Educação Nacional - LDB (Lei n 9394/96), apresenta as seguintes determinações no que diz respeito à gestão democrática, através das quais se pode considerar que a gestão democrática é ampliada, explicitando que:

Art. 12. Os estabelecimentos de ensino, respeitadas as normas comuns e as do seu sistema de ensino, terão a incumbência de:

VI - Articular-se com as famílias e a comunidade, criando processos de integração da sociedade com a escola;

Art. 13. Os docentes incumbir-se-ão de:

I - Participar da elaboração da proposta pedagógica do estabelecimento de ensino;

VI - Colaborar com as atividades de articulação da escola com as famílias e a comunidade.

Art. 14 - Os sistemas de ensino definirão as normas da gestão democrática do ensino público na educação básica, de acordo com as suas peculiaridades e conforme os seguintes princípios:

I. Participação dos profissionais da educação na elaboração do projeto pedagógico da escola;

II. Participação das comunidades escolar e local em conselhos escolares ou equivalentes.

Art. 15 - Os sistemas de ensino assegurarão às unidades escolares públicas de educação básica que os integram progressivos graus de autonomia pedagógica e administrativa e de gestão financeira, observadas as normas de direito financeiro público.

(Brasil, 1996)

Os artigos da LDB supracitados apontam para uma gestão democrática do ensino público na Educação Básica, oferecendo larga autonomia aos Estados para definirem em consonância com os sistemas de ensino escolar (incluído neste aspecto os profissionais envolvidos no processo educacional bem como a comunidade escolar e local) e as formas de operacionalização da gestão (Rodrigues; Santos, 2011).

A forma de lidar com os processos que permeiam a gestão transpassam a cadeia objetiva da solução de problemas, podendo ser compreendida de forma ampla, sendo a gestão democratizada da escola entendida como:

o processo de mediação das relações intersubjetivas, compreendendo, antes e acima das rotinas administrativas: identificação de necessidades; negociação de propósitos; definição clara de objetivos e estratégias de ação; linhas de compromissos; coordenação e acompanhamento de decisões pactuadas; mediação de conflitos, com ações voltadas para a transformação social.

(Bordignon; Gracindo, 2000, apud, Ferreira; Aguiar, 2000, p. 164)

A autonomia, portanto, no sistema educacional, por que não dizer da escola, é conquistada pelo exercício da autonomia dos seus sujeitos - sujeitos coletivos, na expressão de Silva (2002) - que precisam constituir-se como grupo e criarem suas identidades.

Sendo assim, a autonomia é, por isso, uma maneira de gerir, orientar, as diversas dependências em que os indivíduos e os grupos se encontram no seu meio biológico ou social, de acordo com as suas próprias leis (Forno; Ferreira; Markowicz, 
2012).

Como visto no que foi citado acima, o pilar de complementaridade da autonomia para o alicerce dessa nova prática de gestão educacional é a gestão pública participativa, que vem fazendo parte do rol das orientações que são planejadas pelas instituições sociais coordenadas pelo poder central que implanta e/ou implementa programas, e que tem o poder decisório de definir quais instrumentos serão viáveis, para que a população escolar possa participar das decisões. Tais instrumentos são os conselhos, os fóruns de representação e de debates que tem como objetivo reunir os diversos segmentos da sociedade civil, a fim de consolidar o sistema de participação social proposto pelo Governo Federal (Aranda, 2010).

Dentre esses instrumentos da participação social, destacam-se os Conselhos Escolares, que, como mostra Khoury (2007), são órgãos colegiados que representam as comunidades, escolar e local, e que atuam juntamente com a parte administrativa da escola visando definir as estratégias mais pertinentes para tomar decisões administrativas, financeiras e político-pedagógicas harmônicas com as necessidades e potencialidades da escola.

A composição, funções, responsabilidades e funcionamento dos Conselhos Escolares devem ser estabelecidos pelos sistemas de ensino e pela própria escola, a partir de sua realidade concreta e garantindo sua natureza essencialmente políticopedagógica. Todas as pessoas ligadas à escola podem representar e decidir sobre aspectos administrativos, financeiros e pedagógicos, tornando este colegiado não só um canal de participação, mas também um instrumento de gestão da própria escola (Khoury, 2007).

Em outro ponto não distante, os programas "Democratização da Gestão nos Sistemas de Ensino" e "Gestão da Política de Educação" foram criados com o intuito de favorecer a promoção e fortalecimento de participação na gestão educacional pública. Apontando em especial para o "Programa Gestão da Política de Educação", foi possível constatar que o mesmo vem sendo materializado pelo "Programa Nacional de Fortalecimento dos Conselhos Escolares" (Brasil, 2004b), diretamente voltado para as Secretarias de Educação e suas Unidades Escolares de Educação Básica.

Com isso, é possível perceber que o Programa Nacional de Fortalecimento dos Conselhos Escolares surgiu com a proposta de fomentar e fortalecer a gestão democrática nos Estados e municípios, ou seja, descentralizando de forma única em cada esfera de governo e assegurando a implementação de forma continuada e eficaz da política educacional, buscando legitimar mecanismos de participação e de controle social, por meio de organizações colegiadas, visando o resgate à cidadania.

Por mais que se tenham bases legais que assegurem no papel o exercício democrático da gestão na educação, é necessária uma mudança de um paradigma, ou seja, modelo com preceito positivista, e caminhar rumo à construção de um novo modelo de gestão, o da superação da verticalidade das relações, fruto original de toda a hierarquia de poder no sistema e na escola, investindo em um modelo de gestão que gere participação, corresponsabilidade e compromisso, numa concepção de educação desenvolvida no eixo da horizontalidade e que aponte para o verdadeiro resgate da qualidade do ensino e para a formação da cidadania (Lima, 2002).

\subsection{Gestão Educacional como subsídio para os avanços na Educação do Piauí no contexto do Ensino básico}

Antes de explanar o que será discutido nesta categoria, é necessário conceituar o que é educação básica ou ensino básico. A educação básica é entendida como o primeiro nível do ensino escolar no Brasil. Compreende três etapas: a educação infantil (para crianças com até cinco anos), o ensino fundamental (para alunos de seis a 14 anos) e o ensino médio (para alunos de 15 a 17 anos) (Brasil, 2012).

\subsection{Prêmio Gestão Escolar como Incentivo à Melhoria da Educação}

No Piauí, a gestão escolar vem passando por diversas transformações no que tange o aprimoramento da administração educacional. Um dos pontos que justificam essa afirmativa é número de escolas participante do Prêmio Gestão Escolar (PGE), 
que fomenta a melhoria do sistema educacional e foi instituído pelo Conselho Nacional de Secretários da Educação - CONSED - em 1988 e no Piauí em 1999. Esse projeto passou alguns anos sem ser realizado sendo resgatado no Piaú em 2010 (Seduc-PI, 2012).

Desde o surgimento do PGE, a Secretaria de Estado da Educação e Cultura do Piaú́ (Seduc-PI) vem mobilizando as escolas e informando sobre a importância da participação no prêmio. Na primeira edição do prêmio no Estado, em 2010, estavam escritas 19 escolas. Em 2011, o número passou para 49 e em 2012 o número de escolas participantes subiu para 132 (Seduc-Pi, 2013a).

O aumento do número de escolas inscritas no PGE se dá também pela mobilização das escolas da rede pública estadual e municipal, para que sejam realizadas as inscrições no processo de Autoavaliação da Gestão Escolar e Elaboração do Plano de Melhoria da Gestão Escolar, o chamado dia "D” (Seduc-Pi, 2013b).

Além das escolas, a Secretaria Estadual de Educação e Cultura do Piauí, também difunde a ação de mobilização nas Gerências Regionais - GRE's. Tudo isso em prol de que as escolas públicas mostrem o desenvolvimento de suas gestões, além de incentivar o processo de melhoria contínua na escola, pela elaboração de planos de ações, tendo como base uma autoavaliação (Seduc-Pi, 2013c).

O PGE foi instituído para estimular o desenvolvimento da gestão democrática na escola, tendo como foco o compromisso com uma aprendizagem de qualidade; valorizar as escolas públicas de educação básica que se destaquem pela competência de sua gestão e por iniciativas e experiências inovadoras e bem-sucedidas na melhoria da aprendizagem dos alunos; apoiar o desenvolvimento de uma cultura de autoavaliação da gestão escolar e incentivar o processo de melhoria contínua na escola (Seduc-Pi, 2013d).

No ano de 2013, a Unidade Escolar José Alves Bezerra, situada na cidade de Monsenhor Hipólito, a 360 km de Teresina, foi uma das escolas campeãs do PGE. O prêmio visa estimular à melhoria do desempenho da escola e ao sucesso da aprendizagem dos alunos dando visibilidade às instituições, tornando-as referência nacional, por desenvolverem práticas eficazes de gestão. As escolas representantes dos Estados e do Distrito Federal recebem o diploma de destaque estadual/distrital e o valor de R \$ 6 mil, para investimentos na Escola. Os diretores selecionados de todas as instituições de ensino representam suas escolas e também são contemplados com uma viagem de intercâmbio para os Estados Unidos (SeducPI, 2013d).

\subsection{Programa Intercâmbio como Fortalecimento das Ferramentas de Gestão}

O Programa Brasil-Estados Unidos de Intercâmbio de diretores escolares possibilita a troca de experiências entre os gestores escolares, a fim de maximizar o campo de atuação do gestor, propondo ações inovadoras que estimulem ainda mais a capacidade de trabalho em equipe através da gestão democrática, sendo o maior reflexo desse processo o melhor rendimento do aluno. É exemplo disso, a visita técnica realizada pela diretora de uma escola do Estado americano do Texas às escolas de Teresina e do interior do Piauí (Seduc-Pi, 2013e).

Um dos pontos desta visita foi o Centro de Ensino Médio de Tempo Integral (CEMTI) Desembargador Pedro Sá, em Oeiras, destaque também no PGE. A gestora do Centro participou do mesmo intercâmbio no ano de 2013, tendo a oportunidade de conhecer de perto a realidade da escola pública nos Estados Unidos da América - EUA, onde participou de vivências e experiências exitosas com aspectos comparativos entre o sistema educacional no Brasil e nos EUA (Seduc-Pi, 2013e).

\subsection{Importância da Capacitação dos Gestores na Construção do Avanço Educacional no Piauí}

Outro ponto que fortalece e põe em destaque a educação do Piauí, é a criação dos programas de capacitação de 
gestores, como por exemplo, o programa Progestão Online, desenvolvido pela Secretaria de Estado da Educação e Cultura (Seduc), através do Centro de Referência em Formação dos Profissionais da Educação/ Instituto de Educação Antônio Freire (SEDUC-PI, 2013f).

O Progestão Online é um curso de capacitação direcionado para gestão escolar, que teve início em maio de 2012 e é organizado em 10 módulos que tratam de temas como sucesso e permanência de alunos na escola, projeto pedagógico, avaliação institucional, gerenciamento financeiro, espaço físico, patrimônio da escola e recursos humanos. O curso é uma iniciativa do Conselho Nacional de Secretários de Educação (Consed) para formação em gestão administrativa e pedagógica de gestores de escolas públicas. O curso tem como público alvo professores que se encontram na gestão de escolas, assumindo as funções de diretores, coordenadores e supervisores escolares (Seduc-PI, 2013f).

Outro item que também estimula o fomento para novas perspectivas na gestão da educação no Piauí é a experiência vivida, no Estado, através do e-Tec, que tem como finalidade desenvolver a Educação Profissional Nacional de Acesso ao Ensino Técnico e Emprego (PRONATEC) e tem como finalidade desenvolver a educação Profissional e tecnológica na modalidade de educação à distância (MEC, 2014).

No Piauí, a Educação à Distância está presente em 60 municípios, nesta modalidade, sendo realizada com recursos próprios do Estado, com exceção das bolsas concedidas aos tutores, financiadas pelo Governo Federal. Os cursos acontecem desde 2011 em parceria com Instituto Federal de Educação do Piauí (Ifpi). No ano de 2013 a expansão aconteceu para 38 novos polos, com a oferta de cinco cursos: Informática, Enfermagem, Agropecuária, Administração e Logística (Seduc-Pi, 2013g).

No tocante à capacitação dos gestores para a promoção da educação, teve início também no ano de 2013, o Curso de Especialização em Gestão Escolar desenvolvido pela Universidade Federal do Piauí-UFPI, em parceria com a Seduc-PI. O curso faz parte do programa Nacional Escola de Gestores da Educação Básica, que é realizado, no Piauí, através de uma parceria entre a UFPI, Seduc e Undime (União Nacional dos Dirigentes Municipais da Educação), voltado para a educação continuada (Seduc-Pi, 2013g).

\section{Considerações Finais}

É inquestionável o aprimoramento da gestão nos serviços educacionais, uma vez que a qualidade do ensino está diretamente ligada às novas ferramentas e modelos inovadores no que diz respeito à forma de administrar, mostrando-se como instrumento de mudança no processo da construção da melhoria educacional.

Todo esse processo da nova construção do saber é amplamente visível a partir do momento em que se considera a democratização na gestão educacional como um instrumento que amplia a perspectiva do desenvolvimento da educação, pautado em uma gestão co-participativa, com garantia da autonomia dos gestores e responsabilidades bem delimitadas. A democratização da educação é sem dúvidas, um dos pilares de sustentação do novo modelo da gestão educacional.

Como fruto deste processo, é importante considerar o papel dos programas que incentivam as instituições de ensino a buscar o máximo de qualidade. Isso pode ser demonstrado com clareza na importância do Prêmio Gestão Escolar, que impulsiona as escolas pela procura de uma melhor educação através da implementação de modelos gerenciais cada vez mais participativos e democráticos, considerando todos os envolvidos no processo da formação do saber como atores que edificam o sistema ensino. Nessa interface, o Estado do Piauí é um propulsor no que tange a gestão participativa na educação, mostrando números expressivos de compromisso e responsabilidade através da notoriedade dada ao Estado pelo seu sistema educacional.

Complementar a isso, outro exemplo que contempla esse modelo inovador na gestão da educação no Piauí são os programas de capacitação de gestores, que incentivam ainda mais os administradores a manterem o compromisso com a educação, introduzindo novas estratégias no que diz respeito à maneira de gerir, subsidiando o conhecimento e aperfeiçoando 
as ferramentas de gestão.

\section{Referências}

Aranda, M. A. M (2010). A participação como ponto de convergência na gestão da política educacional dos anos iniciais do século XXI. Anais do XV Endipe - encontro nacional de didática e prática de ensino. Convergências e tensões no campo da formação e do trabalho docente: políticas e práticas educacionais.

Bacelar, L. P. (2008). O papel do Conselho Escolar para a democratização da gestão. Fortaleza: UEC.

Brasil. Lei de Diretrizes e Bases da Educação Nacional. Lei no 9.394, de 20 de dezembro de 1996 (1996). <http://www.portal.mec.gov.br>. Acesso em: 20 jun. 2021.

Brasil. Constituição (1988). Constituição da República Federativa do Brasil. Senado Federal: Centro Gráfico.

Brasil. Portal Brasil (2012). Etapas do ensino asseguram cidadania para crianças e jovens. <http://www.brasil.gov.br/educacao/2012/04/etapas-do-ensinoasseguram-cidadania-para-criancas-e-jovens>.

Brasil. Ministério da Educação e Cultura (MEC) (2006). Brasil. Secretaria de Educação Básica. B823 Gestão da educação escolar / Luiz Fernandes Dourado. Universidade de Brasília, Centro de Educação a Distância. (Curso técnico de formação para os funcionários da educação. Profuncionário).

Brasil. MEC (2004a). Conselho Escolar - gestão democrática da educação e escolha de diretor. Programa nacional de fortalecimento dos conselhos escolares.

Brasil. Programa Nacional de Fortalecimento dos Conselhos Escolares (2004b). Instituído pela Portaria Ministerial nº 2.896 , de 17 de setembro de 2004. $\mathrm{MEC} / \mathrm{SEB}$.

Brasil. Educação Profissional e Tecnologia na Modalidade a Distância (2020). Rede e-Tec <http://redeetec.mec.gov.br/index.php/home> .

Bordignon, G., \& Gracindo, R. V. (2000). Gestão da Educação: o município e a escola. In: FERREIRA, N; AGUIAR, M. (orgs.). Gestão da Educação: impasses, perspectivas e compromissos. Cortez.

Ferreira, A. B. H. (2010) Mini Aurélio: o dicionário da Língua Portuguesa. (8a ed.), Positivo.

Forno, M. R. G. D, Ferreira, N. S. C., \& Markowicz, D (2012). Gestão da educação e formação de professores: experiências de uma escola estadual do Paraná. Seminário de Pesquisa em Educação da Região Sul.

Gil, A. C (2007). Métodos e técnicas de pesquisa social. Atlas.

Khoury, C. G. (2007). A importância do processo de gestão democrática para o desenvolvimento sócio-moral da criança. Pedagogia em Foco. <http://www.pedagogiaemfoco.pro.br/edinf03.htm>.

Lakatos, E. M., \& Marconi, M. A (2003). Fundamentos de metodologia científica. Atlas.

Lima, M. A. S. (2002) A gestão democrática da escola e seu papel emancipatório na nova sociedade do conhecimento <http://www.ufpi.br/subsiteFiles/ppged/arquivos/files/eventos/evento2002/GT.4/GT4_6_2002.pdf>.

Mendonça, E. (1998). A gestão democrática nos sistemas de ensinos brasileiros: a intenção e o gesto. (UnB). < http://www.sinprodf.org.br/wpcontent/uploads/2012/01/gestao_democratica_nos_sistemasdeensino.pdf>.

Paro, V. H. (1998) Gestão Democrática da escola pública. Ática.

Rodrigues, M. M., \& Santos, C. O. F. (2011). Gestão educacional: inovações, limites e possibilidades. Acta Scientiarum. Education. 33

Sarubi, É. R. (2006). Gestão democrática: repercussões na identidade e profissão dos diretores escolares. In: Seminário da redestado - regulação educacional e trabalho docente, 6., Rio de Janeiro. Anais... UERJ.

Secretaria da Cultura do Piauí (SEDUC-PI) (2012). Piauí. Portal do Governo do Estado do Piauí. Seduc entrega Prêmio que valoriza a gestão escolar de referência na educação básica pública. <http://www.seduc.pi.gov.br/noticia.php?id=214>.

Secretaria da Cultura do Piauí (2013). Piauí. Portal do Governo do Estado do Piauí. Escolas do Piauí avançam e são contempladas com o Prêmio Gestão Escolar. <http://www.seduc.pi.gov.br/noticia.php?id=1476>.

Secretaria da Cultura do Piauí (2013). Piauí. Portal do Governo do Estado do Piauí. Prêmio Gestão Escolar realiza Dia "D”. <http://www.seduc.pi.gov.br/noticia.php?id=1002>.

Secretaria da Cultura do Piauí (2013). Piauí. Portal do Governo do Estado do Piauí. SEDUC mobiliza Gre's para o Prêmio Gestão Escolar. http://www.seduc.pi.gov.br/noticia.php?id=875>.

Secretaria da Cultura do Piauí (2013). Piauí. Portal do Governo do Estado do Piauí. Escola do Piauí está na lista das escolas campeãs do Prêmio Gestão Escolar 2013. <http://www.seduc.pi.gov.br/noticia.php?id=1377>.

Secretaria da Cultura do Piauí (2013). Piauí. Portal do Governo do Estado do Piauí. Escolas estaduais de Oeiras recebem diretora norte-americana com festa. < http://www.seduc.pi.gov.br/noticia.php?id=1350>.

Secretaria da Cultura do Piauí (2013). Piauí. Portal do Governo do Estado do Piauí. Seduc forma cerca de 700 gestores no Progestão Online. < http://www.seduc.pi.gov.br/noticia.php?id=1270>. 
Research, Society and Development, v. 10, n. 8, e55710817692, 2021

(CC BY 4.0) | ISSN 2525-3409 | DOI: http://dx.doi.org/10.33448/rsd-v10i8.17692

Secretaria da Cultura do Piau (2013). Piaú. Portal do Governo do Estado do Piauí. Curso de Especialização em Gestão Escolar contempla 300 gestores. <http://www.seduc.pi.gov.br/noticia.php?id=1604.>

Silva, J. M. A. (2002). Autonomia da Escola Pública: a re-humanização da escola. Papirus. 